\title{
Pediculus capitis: Terapias disponibles
}

\author{
ROBERTO P. ROSSO A. ${ }^{1}$, M. SOLEDAD RAMÍREZ G ${ }^{1}$ y MARISA TORRES H. ${ }^{2}$
}

\section{Pediculus capitis: Available therapies}

Head lice infestation is very common. It is one of most frequent diseases in the childhood. In $1996,15 \%$ of the people in the world and $30 \%$ of infant were infected. The drugs used at the moment are very effective but the people get reinfested after two months, so to avoid it, it is important to treat all contacts. There are different active compounds like lindane, pyrethins, crotamiton, thiabendazole, malathion, carbaryl and sulpha/trimethoprim. For each of these, we discuss their action, pharmacology characteristics, effectiveness and adverse effects.

Key words: Pediculosis capitis, Pediculus humanus, Lindane, Head lice.

\section{Introducción}

Pediculosis es la infestación del hombre por Pediculus humanus, ectoparásito perteneciente al orden Anoplura, y a la familia Pediculidae. De él existen dos variedades: del cuero cabelludo (Pediculus capitis) y del cuerpo (Pediculus corporis o vestimentis).

La infestación por $P$. humanus variedad capitis es una de las enfermedades más frecuentes de la infancia; en 1996, según datos publicados, afectaba a más de $15 \%$ de la población general y a más de $30 \%$ de la población infantil ${ }^{1}$.

$P$. humanus, es un insecto hematófago, deprimido dorsoventralmente, de forma alargada, que mide entre 2 y $4 \mathrm{~mm}$ de longitud y que carece de alas. Posee una metamorfosis gradual o incompleta.

Los fármacos actualmente utilizados son de gran eficacia, pero cerca de $20 \%$ de la población se ha reinfestado ya a los 2 meses, por lo que para evitar recidivas se sugiere efectuar tratamiento a todos los contactos del paciente. Las principales causas de falla en el tratamiento se pueden apreciar en la Tabla 1. En algunos casos, antes de iniciar la eliminación del parásito, se debe aplicar un tratamiento sintomático del prurito con antihistamínicos y, si hay evidencia de infección bacteriana secundaria, efectuar terapia antimicrobiana sistémica.

Entre los fármacos más usados actualmente, están: lindano, derivados piretroides, crotamitón, tiabendazol, malatión, carbaryl y cotrimoxazol.

Tabla 1. Causas más frecuentes de falla terapéutica en el tratamiento de $\boldsymbol{P}$. capitis

- Reinfestación (lo más común).

- Comprensión errónea de las instrucciones por parte del paciente.

- Instrucciones inapropiadas sobre el uso de los productos pediculicidas por parte de los profesionales de la salud.

- Alto costo de los productos.

- Diagnósticos erróneos.

- Actividad ovicida incompleta.

- Preparación inapropiada del producto.

- Insuficiente dosis, tiempo de aplicación, frecuencia y/o cantidad de producto aplicado.

- Prurito psicógeno.

- Fallas en la reaplicación.

- Liendres vivas no removidas.

- Resistencia adquirida a los diferentes productos.

Facultad de Medicina. Pontificia Universidad Católica de Chile:

${ }^{1}$ Estudiante de Medicina

${ }^{2}$ Departamento de Parasitología

Recibido: 26 septiembre 2002

Aceptado: 8 mayo 2002 
De cada uno se menciona su mecanismo de acción, características farmacológicas, efectividad y efectos adversos. En la Tabla 2 aparecen los compuestos activos y las formas comerciales disponibles actualmente, destacando su forma de presentación, modo y precauciones para su uso.

Tabla 2. Compuestos pediculicidas disponibles en Chile

\begin{tabular}{|c|c|c|}
\hline $\begin{array}{l}\text { Principio } \\
\text { activo }\end{array}$ & $\begin{array}{l}\text { Contenido } \\
\text { (Nombre comercial) }\end{array}$ & Presentación y modo de uso \\
\hline Crotamitón & $\begin{array}{l}\text { Crema y loción al } 10 \% \\
\text { N-crotonil-N-etil-o-toluidina. } \\
(10 \text { g) } \\
\text { Excipientes cs. } \\
(\text { Clamox } ®, \text { Crotamitón } \AA \text {, } \\
\text { Eurax } ®, \text { Sundar } ®)\end{array}$ & $\begin{array}{l}\text { Crema y loción al } 10 \% \text {. } \\
\text { Aplique luego del lavado del cabello con agua caliente y champú, } \\
\text { friccionando el cuero cabelludo, especialmente zona retroauricular } \\
\text { y occipital. } \\
\text { Los cabellos húmedos se peinan con un peine de dientes finos. } \\
\text { Deje secar el cabello y no lave en } 24 \text { horas. Repita a los } 7 \text { días. }\end{array}$ \\
\hline Decametrina & $\begin{array}{l}\text { Decametrina } 0,2 \mathrm{~g} \\
\text { Butóxido de piperonilo } 2 \mathrm{~g} \\
\text { Excipientes c.s. } \\
\text { (Decametrina }{ }^{\circledR} \text { ) }\end{array}$ & Loción en envases de 60 y 120 ml. \\
\hline Decametrina & $\begin{array}{l}\text { Decametrina } 20 \text { mg. } \\
\text { (Nopucid } ® \text { ) }\end{array}$ & $\begin{array}{l}\text { Loción o champú en envase de } 100 \mathrm{ml} \\
\text { Aplique en cuero cabelludo, deje toda la noche, repita el tratamiento } \\
\text { al día siguiente y una semana más tarde. }\end{array}$ \\
\hline Decametrina & $\begin{array}{l}\text { Decametrina } 0,02 \mathrm{~g} \\
\text { Butóxido de piperonilo } 2,5 \mathrm{~g} \\
\text { (Nopucid compuesto } ® \text { ) }\end{array}$ & $\begin{array}{l}\text { Loción o champú en envase de } 100 \mathrm{ml} \\
\text { Aplique en el cuero cabelludo en la noche y lave a la mañana siguiente. } \\
\text { Repita al } 2^{\circ} \text { día y una semana más tarde. }\end{array}$ \\
\hline Deltametrina & $\begin{array}{l}\text { Deltametrina } 0,02 \mathrm{~g} \\
\text { Piperonil butóxido } 2,5 \mathrm{~g} \text {. } \\
\text { (Launol loción } \AA \text {, Launol } \\
\text { champú } \AA \text {, Launol plus } \\
\text { shampoo } \circledR \text { ) }\end{array}$ & $\begin{array}{l}\text { Loción y champú. } \\
\text { Aplique como champú habitual, masajee hasta obtener espuma. } \\
\text { Enjuagar luego de } 10 \text { min. Seque el cabello y pase el peine de dientes } \\
\text { finos. Repita si se encuentran parásitos vivos. }\end{array}$ \\
\hline Lindano $1 \%$ & 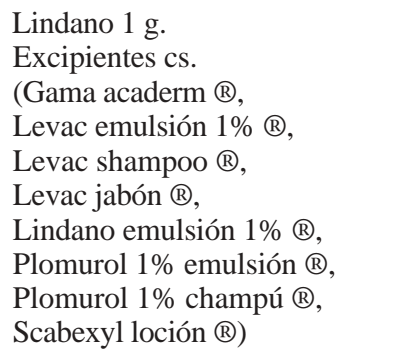 & $\begin{array}{l}\text { Loción, champú, jabón (barra de } 100 \text { gr) } \\
\text { Lave cabello con agua tibia, aplique por } 10 \text { min y luego enjuague. } \\
\text { Pase peine de dientes finos para eliminar restos de parásitos. } \\
\text { Repita a los } 7 \text { días. }\end{array}$ \\
\hline Lindano $10 \%$ & $\begin{array}{l}\text { Cada } 1.000 \mathrm{~g}: \\
\text { Lindano } 100 \mathrm{~g} \\
\text { Excipientes c.s } \\
\text { (Lindano emulsión } 10 \% \text { ®) }\end{array}$ & $\begin{array}{l}\text { Envase de } 1 \mathrm{~kg} \text {, } \\
\text { Solución madre para dilución. }\end{array}$ \\
\hline Permetrina & $\begin{array}{l}\text { Permetrina } 1 \mathrm{~g} . \\
\text { Excipientes cs. } \\
\left.\text { (Bichol } ® \text {, Dertil }{ }^{\circledR}, \text { Kilnits } ®\right)\end{array}$ & $\begin{array}{l}\text { Champú. } \\
\text { Lave el cabello con el producto, enjuagar con abundante agua luego de } \\
10 \text { min. Repita a los } 7 \text { días. }\end{array}$ \\
\hline Piretrinas & $\begin{array}{l}\text { Butóxido de piperonilo: } \\
\text { 2,65g Piretrinas: } 0,3 \mathrm{~g} \\
\text { Compuestos relacionados } \\
0,35 \mathrm{~g} \text { (Quitoso } ®)\end{array}$ & $\begin{array}{l}\text { Loción. } \\
\text { Aplique sin diluir sobre el cuero cabelludo, deje por } 10 \text { min, enjuagar } \\
\text { con agua caliente. Use peine para remover restos. Repita a los } 7-10 \\
\text { días si fuera necesario. }\end{array}$ \\
\hline $\begin{array}{l}\text { Peine de } \\
\text { precisión }\end{array}$ & \multicolumn{2}{|c|}{$\begin{array}{l}\text { Peine con mango anatómico. Hervible. Lave el cabello y pase el peine a ras del cuero cabelludo, } \\
\text { mechón por mechón en secciones de no más de } 4 \mathrm{~cm} \text {, asegurándose de cubrir todo el cabello hasta } \\
\text { retirar todos los piojos y liendres. }\end{array}$} \\
\hline
\end{tabular}

* El contenido de cada uno de los productos se encuentra expresado por cada $100 \mathrm{ml}$ o $100 \mathrm{~g}$, según sea el caso.

* Las indicaciones de uso, están definidas en términos generales. Para cada producto, deberán adecuarse a las instrucciones del laboratorio que las fabrica. 
Tabla 3. Muestra las principales precauciones que se debe tener frente al uso de cualquiera de las sustancias señaladas en la tabla 2

\section{Precauciones:}

- No exceda las dosis señaladas.

- No aplique sobre piel dañada o infectada.

- Posible irritación cutánea o alergia por contacto.

- Suspenda en caso de picazón, eritema o edema.

- Evite contacto con mucosas, inhalación e ingestión

- Evite durante embarazo y lactancia.

- En menores de 1 año, use bajo prescripción médica

- En niños pequeños no aplique en áreas extensas.

- No debe ser ingerido.

- Contraindicado en pacientes con hipersensibilidad a los componentes del preparado.

- Lindano (gamma hexacloruro de benceno): se usa contra $P$. capitis en solución al $1 \%$. Se aplica en forma tópica, durante 6 a 24 horas, debiendo repetirse a la semana, pues carece de actividad ovicida. En nuestro medio es el tratamiento más usado por su bajo costo y los buenos resultados obtenidos en términos epidemiológicos ${ }^{1}$. Su uso tópico podría provocar reacciones de hipersensibilidad local. Se absorbe en $\sim 10 \%$, pasando a la circulación sanguínea, donde su vida media es de 24 horas; su eliminación es predominantemente renal $^{2}$. A largo plazo, se acumula en el tejido adiposo y en el cerebro. Puede excretarse en la leche materna, aunque generalmente las concentraciones alcanzadas no llegan a ser consideradas tóxicas. Una de las mayores desventajas del lindano es carecer de olor y ser insípido, pudiendo ser ingerido accidentalmente. En estos casos, y en aplicaciones tópicas reiteradas con concentraciones excesivas, se pueden observar diversos efectos tóxicos; entre ellos, el compromiso del SNC es el más importante, pudiendo desencadenar convulsiones e incluso la muerte. El vapor emanado al diluir una solución madre, podría irritar los ojos o la vía respiratoria alta. En comparación a otros fármacos, es menos efectivo que permetrina $(71 \%)$, posiblemente por carecer de actividad ovicida ${ }^{1}$. Se han descrito algunos casos de resistencia. Rango de toxicidad: en adultos, la dosis letal en una ingestión oral corresponde a $28 \mathrm{~g}$, pero se ha descrito que ingestiones de $45 \mathrm{mg}$ pueden ya causar cierto compromiso sistémico; en niños bajo 4 años de edad, dosis de $5 \mathrm{ml}$ al $1 \%$ puede causar depresión respiratoria. Su ingestión al 95 o $100 \%$, aún en dosis mínimas, generalmente produce toxicidad $^{3}$. Se recomienda no usar en prematuros ni en personas con trastornos convulsivos, debido a su potencial acción sobre el SNC. Aunque en humanos no se le han comprobado efectos teratogénicos, ni inducción de un aumento de abortos espontáneos, debe utilizarse con precaución en niños, lactantes y mujeres embarazadas.

Impacto ambiental: Un estudio norteamericano determinó que lindano era uno de los contaminantes más comunes de los ecosistemas acuáticos, encontrándose incluso en el tejido de algunos peces ${ }^{4}$; otra investigación determinó que esta sustancia no sólo reducía la tasa de crecimiento de ciertos insectos acuáticos, sino, que en concentraciones mayores, podía ser letal para ellos ${ }^{5}$. Un artículo japonés publicado en el año 2001, señaló que residuos de diferentes pesticidas, entre ellos los isómeros de hexacloruro de benceno, fueron encontrados en suelo, aves, peces y otros seres provenientes del sur de India ${ }^{6}$. Un estudio contemporáneo alemán detectó lindano en el polvo de las aspiradoras, lo que sugiere que se encuentra también al interior de los hogares analizados ${ }^{7}$.

\section{- Derivados piretroides}

Decametrina 0,2\%: Se han obtenido buenos resultados con dos aplicaciones de esta sustancia (una cada 7 días), aunque han sido descritos numerosos casos de sensibilización y dermatitis de contacto, asociadas a escoriaciones.

Piretrinas: Sustancias de uso tópico extraídas desde los crisantemos, que se presentan como champú. Por carecer de actividad ovicida, debe repetirse su aplicación 7 días después. Parecen ser tanto o más efectivas que lindano. Se han presentado reacciones alérgicas en pacientes sensibles pero, con técnicas cada vez más depuradas, este tipo de riesgos se ha reducido significativamente.

Permetrina: Piretroide sintético con efecto neurotóxico para $P$. humanus, Pthirus pubis y Sarcoptes scabiei. Se utiliza en solución al 1 a $3 \%$. Su actividad pediculicida continúa durante 10 a 14 días, lo que permitiría emplear una dosis única; sin embargo, la experiencia muestra mejores resultados luego de aplicar una segunda dosis, por lo que se recomienda repetirla después de 7 días del tratamiento inicial, 
especialmente en familias numerosas y en brotes epidémicos escolares. Debido a su alta actividad pediculicida, y a sus bajos efectos tóxico-residuales (menos de $2 \%$ se absorbe por vía percutánea ${ }^{2}$ ), se perfila como un mejor tratamiento que lindano. Se han descrito casos de resistencia a éste y a otros piretroides ${ }^{8,13}$. Su prescripción está contraindicada durante la gestación y la lactancia natural.

Cabe señalar que los derivados piretroides son sustancias biodegradables, y que la toxicidad de las piretrinas naturales en los mamíferos es baja. Los niños pequeños son quizás los más susceptibles al envenenamiento, debido a que no hidrolizan eficientemente los ésteres de piretroides. Pese a no ser primariamente irritantes, el principal efecto adverso de estos compuestos es la dermatitis. La lesión más común es una dermatitis eritematosa leve, con vesículas, pápulas en áreas húmedas y un intenso prurito. Las piretrinas también pueden causar dermatitis alérgicas severas y reacciones alérgicas sistémicas. Su inhalación puede provocar una reacción de hipersensibilidad sobre las vías aéreas. La ingestión de las piretrinas puede producir fatiga, cefalea, anorexia, náuseas y vómitos. La ingestión masiva (200-500 ml) de fórmulas concentradas, podría llevar rápidamente al coma. Se han descrito efectos cardiovasculares, neurológicos e inmunológi$\cos ^{3}$. La dosis mínima letal en casos de ingestión oral en adultos está en el rango de 10 a $100 \mathrm{~g}^{3}$.

Estudios recientes avalan la aparición de resistencia a permetrina en grados variables, así como también de resistencia cruzada con medicamentos similares ${ }^{8}$, encontrándose incluso una doble resistencia a permetrina y malatión, hecho que podría explicarse por ser ambos, componentes básicos de gran parte de los tratamientos contra pediculosis en países como Inglaterra ${ }^{9}$.

- Crotamitón (N-etil-0-crotonotoluidido): pediculicida y escabicida de uso tópico. Se expende en crema o loción al 10\% que también contiene sulfato de oxiquinolina. Los preparados generalmente tienen propiedades antipruriginosas. El principal efecto adverso de su uso es una dermatitis de contacto, especialmente en piel previamente inflamada, o cuando es aplicado por tiempo muy prolongado. No hay estudios concluyentes respecto a su absorción percutánea ${ }^{2}$. Su ingestión podría causar somnolencia, náuseas, vómitos, hipotensión, compromiso general e incluso, coma con hiperreflexia. No se han descrito efectos carcinogénicos ${ }^{3}$.
- Malatión (fósforoditiotato de 0,0-dimetilo S(1,2-dicarboetoxietilo)): Inhibidor de la acetilcolinesterasa del grupo de los tiofosfatados, ampliamente usado en Europa como insecticida. Es considerado un eficiente pediculicida con cierta actividad ovicida. Se presenta como loción de uso tópico en solución al 0,5\%, la que debe ser rociada sobre el cabello seco y masajeada hasta que el cuero cabelludo se humedezca. Debe permitirse un secado natural ya que es degradado por el calor, lo que impide el uso de secador de pelo. Se recomienda removerlo sólo luego de 8 a 12 horas, pues es absorbido por la queratina, proceso que toma alrededor de 6 horas; esto permite una protección residual contra la reinfestación, por aproximadamente 6 semanas. Una segunda aplicación debería ser realizada 10 días después, debido a que malatión sólo posee una actividad ovicida parcial. No se han reportado efectos adversos sistémicos con el uso tópico de malatión al $0,5 \%$. Un estudio realizado en 22 voluntarios evidenció la seguridad de su aplicación siempre y cuando se respetaran las instrucciones para su uso ${ }^{10}$. Los insecticidas tiofosfatados se absorben con rapidez por todas las vías, gracias a su liposolubilidad. Una vez en el organismo deben activarse por conversión de análogos oxigenados, proceso muy eficaz en los insectos y en algunos vertebrados. Malatión se metaboliza rápidamente hasta productos inactivos en aves y mamíferos, pero no en los insectos, de ahí que su venta al público sea segura ${ }^{2}$. En casos de ingestión accidental, pueden aparecer efectos colinérgicos como disnea, confusión, diarrea, mareos, somnolencia, sudoración, sialorrea, epífora, o pérdida del control intestinal y urinario. La dosis letal (vía oral), estimada en mamíferos es de $1 \mathrm{~g} / \mathrm{kg}^{3}$. Tal vez una de las mayores limitantes para el uso sea su mal olor, asociado a la liberación de compuestos sulfhidrilos. Su vehículo alcohólico podría causar prurito e irritación ocular. Debido a la falta de mayores estudios, se recomienda no emplear en mujeres embarazadas, ni en niños bajo 6 meses de edad. La lactancia natural debería suspenderse si la madre recibirá el pesticida. En Inglaterra se han descrito casos de resistencia debido a su uso masivo; el mecanismo sería, al parecer, la aparición de estearasas específicas contra malatión ${ }^{9}$. Actualmente, no está disponible en Chile.

- Carbaryl: Inhibidor de la acetilcolinesterasa. Ha sido ampliamente usado en Europa. Es un 
eficiente pediculicida y tiene buena actividad ovicida. Su aplicación y características son similares a las del malatión, aunque no posee actividad residual, por lo que no previene la reinfestación. Estudios recientes en roedores muestran un potencial efecto carcinogénico luego de su uso a largo plazo.

- Tiabendazol: proviene de compuestos sustituidos de benzimidazol, algunos de los cuales manifiestan actividad larvicida total in vitro, lo que sumado a la ausencia de actividad contra otros microorganismos y a su relativa baja toxicidad para los mamíferos, hace recomendable su uso contra algunas parasitosis como la larva migrante cutánea o la triquinosis (uso oral). Puede aplicarse sobre la piel en suspensión al 10\% para el tratamiento de escabiosis o pediculosis, aunque no hay estudios que avalen su eficacia. Tiabendazol es absorbido en forma percutánea, siendo eliminado, con una vida media de 70 minutos $^{11}$. En general las concentraciones séricas no han sido correlacionados con efectos tóxicos ${ }^{3}$. Sólo se han reportado casos aislados de sobredosis, provocados generalmente por ingestión oral mayor a $25 \mathrm{mg} / \mathrm{kg}$, dosis recomendada para el tratamiento de parasitosis sistémicas ${ }^{11}$. Entre los efectos adversos, cabe mencionar los gastrointestinales: anorexia, náuseas, vómitos y diarrea. Se han descrito algunos casos de daño hepático ${ }^{3}$.

- Cotrimoxazol: Este antimicrobiano en dosis estándar podría ser utilizado por vía oral en casos de infestación masiva. Su acción se basa en que tras de ser ingerido por el piojo a través de la succión, actúa eliminando sus bacterias intestinales, esenciales para la síntesis de vitamina $B$ y para metabolizar su alimento, por lo que el parásito moriría. No tiene efecto ovicida. Como antibacteriano se administra por vía oral, tiene una buena absorción y se distribuye por todos los tejidos. Al ser excretado por la orina, su dosis debe ser disminuida a la mitad para los pacientes con clearance de creatinina de 15 a $30 \mathrm{~mL} / \mathrm{min}^{13}$. El esquema aprobado para el manejo de la pediculosis, comprende una duración de 10 días ${ }^{14}$. Un estudio reciente demostró una mayor efectividad de la combinación de este antimicrobiano con permetrina al 1\%, al compararlo con cada uno de estos fármacos usados aisladamente; sin embargo, los grupos tratados fueron pequeños ${ }^{14}$. El cotrimoxazol puede producir todas las reacciones adversas relacionadas con las sulfonamidas ${ }^{12}$. No está aprobado por la FDA como pediculicida.

\section{Comentario}

Debido a que la concentración del fármaco y el tiempo de contacto con el cuero cabelludo son relativamente bajas, y además permiten una aplicación cómoda para el paciente, se recomienda el uso de fármacos que se presenten como loción, por tiempos no inferiores a 6 horas. Respecto a la elección del compuesto activo, no hay un consenso que defina el mejor tratamiento. Luego de considerar su eficacia, y sobre todo la seguridad de su uso, nos parece recomendable el uso de piretroides sintéticos, piretrinas y de malatión, teniendo siempre en cuenta las limitantes de su uso. En 1999, se publicó en Inglaterra un estudio, comparando el uso de diferentes fármacos para el tratamiento de la pediculosis, en él se sugirió el uso de la permetrina ${ }^{15}$.

Hay grupos de pacientes en que el uso de cualquiera de los fármacos señalados entraña serios riesgos para la salud: lactantes bajo 6 meses de edad, mujeres embarazadas o en período de lactancia natural, pacientes con algún grado de hipersensibilidad a alguno de los compuestos del producto. En estos casos se sugiere lo siguiente:

- Método del peine sobre el cabello seco. El cabello del paciente, debe ser cepillado con un peine, caracterizado por la pequeña distancia entre sus dientes. El cepillado debe realizarse sobre cabello seco, desde la raíz hacia distal, evitando dejar zonas sin cepillar. El proceso debe continuar por al menos un minuto luego de que el último piojo haya sido visto y debe ser repetido al menos tres veces en el primer día y luego, dos veces por día durante cinco días. Después de que la última liendre haya sido vista, el procedimiento puede ser reducido a una vez por día, a menos que se detecte algún piojo. El paciente puede ser calificado como libre de piojos y liendres, tres semanas después de que se ha encontrado el último piojo. Se ha comunicado un $100 \%$ de rendimiento en la desinfestación dentro de una semana ${ }^{16}$.

También es posible utilizar el peine sobre cabello húmedo, luego de la aplicación de acondicionador: Debe cepillarse por al menos 30 minutos cada 3 ó 4 días. La efectividad de esta técnica se ve disminuida por la dificultad de ver en el pelo húmedo y lleno de acondicionador, cuántos piojos o liendres han sido removidos. 
El método del peine sobre el cabello seco tiene la gran ventaja de ser usado repetidamente sin temor a la toxicidad; no hay contraindicaciones a su uso ni se ha descrito resistencia. Por otro lado, es preferible este método al de peinado sobre cabello húmedo ya que la eliminación de los piojos puede ser monitorizada.

Es necesario recordar que todos los contactos del paciente deben ser examinados, y de presentar infestación, deben ser tratados, con el fin de evitar la reinfestación. Vestimenta, ropa de cama y otros fomites deben ser lavados con máquina a $60^{\circ} \mathrm{C}$. Se sugiere que elementos como peines o juguetes plásticos, que pueden actuar como fomites, sean desinfectados con algún insecticida apropiado.

\section{Resumen}

Pediculosis es la infestación del hombre por Pediculus humanus, variedad capitis. Es una de las enfermedades más frecuentes de la infancia, en 1996 afectaba a más de 15\% de la población general y a más de $30 \%$ de la población infantil. Los fármacos actualmente utilizados son de gran eficacia, pero hasta $20 \%$ de la población se ha reinfestado a los 2 meses, por lo que para evitar recidivas se debe efectuar tratamiento a todos los contactos del paciente. Hay diversos compuestos activos, entre ellos: lindano, derivados piretroides, crotamitón, tiabendazol, malatión, carbaryl y cotrimoxazol. De cada uno, se discute el mecanismo de acción, características farmacológicas, efectividad y efectos adversos.

\section{Bibliografía}

1.- Perez-Cotapos Subercaseaux M L, Zegpi Trueba M S. Pediculosis y Escabiosis. Boletín Escuela de Medicina Pontificia Universidad Católica de Chile 1996; 25: 40-3.

2.- Robertson D, Maibach H. Farmacología Dermatológica. Farmacología Básica y Clínica, $7^{\circ}$ Edición, 1999, Cap 62; 1157-58.

3.- Base de datos del CITUC, Micromedex Inc vol 88, año 2001.
4.- Eaton H J, Lydy M J. Assessment of water quality in Wichita, Kansas, using an index of biotic integrity and analysis of bed sediment and fish tissue for organochlorine insecticides. Arch Environ Contam Toxicol 2000; 39 (4): 531-40.

5.- Maund S J, Peither A, Taylor E J, Juttner I, BeyerlePfnur R, Lay J P, Pascoe D. Toxicity of lindane to freshwater insect larvae in compartments of an experimental pond. Ecotoxicol Environ Saf 1992; 23 (1): 76-88.

6- Senthilkumar K, Kannan K, Subramanian A, Tanabe S. Accumulation of organochlorine pesticides and polychlorinated biphenyls in sediments, aquatic organisms, birds, bird eggs and bat collected from south India. Environ Sci Pollut Res Int 2001; 8 (1): 35-47.

7.- Seifert B, Becker K, Helm D, Krause C, Schulz C, Seiwert M. The German Environmental Survey 1990/ 1992 (GerES II): reference concentrations of selected environmental pollutants in blood, urine, hair, house dust, drinking water and indoor air. J Expo Anal Environ Epidemiol 2000; 10 (6 Pt 1): 552-65.

8.- Downs A M, Stafford K A, Harvey I, Coles G C. Evidence of double resistance to permethrin and malathion in head lice. Br J Dermatol 1999; 141 (3): 508-11.

9.- Burkhart C G, Burkhart C N. Clinical evidence of lice resistance to over the counter products. Cutan Med Surg 2000; 4 (4): 199-201.

10.- Dennis G A, Lee P N. A phase I volunteer study to establish the degree of absorption and effect on cholinesterase activity of four head lice preparations containing malathion. Clin Drug Invest 1999; 18: 10515 .

11.- Goldsmith R. Farmacología Clínica de los Antihelmínticos. Farmacología Básica y Clínica, $7^{\circ}$ Edición, 1999; Cap 54: 1006-08.

12.- Chambers H, Jawetz E. Sulfonamidas, trimetropim y quinolonas. Farmacología Básica y Clínica, $7^{\circ}$ Edición, 1999, Cap 46; 880-81.

13.- Hemingway J, Miller J, Mumcuoglu K Y. Pyrethoid resistance mechanisms in the head louse Pediculus capitis from Israel: implications for control. Med Ved Entomol 1999; 13: 89-96.

14.- Hipolito R B, Mallorca F G, Zuniga-Macaraig Z O, Apolinario P C, Wheeler-Sherman J. Head lice infestation: single drug versus combination therapy with one percent permethrin and trimethoprim/ sulfamethoxazole. Pediatrics 2001; 107 (3).

15.- Dawes M, Hicks N R, Flemminger M, Goldman D, Hamling J, Hicks L J. Evidence based case report: treatment for head lice. BMf 1999; 318: 385-6.

16.- Roffe C. Treatment of Pediculosis capitis by dry combing. Lancet 2000; 355: 1724.

Correspondencia a:

Roberto P. Rosso A

E-mail: robertorosso@entelchile.net 